\title{
Estimation of soil moisture and its effect on soil thermal characteristics at Astronomical Observatory, Thiruvananthapuram, south Kerala
}

\author{
M S Roxy ${ }^{1, *}, \mathrm{~V}$ B Sumithranand ${ }^{2}$ and G Renuka ${ }^{3}$ \\ ${ }^{1}$ Department of Physics, Sree Narayana College, Kollam 691 001, India. \\ ${ }^{2}$ Govt. Higher Secondary School, Kulathoor, Thiruvananthapuram 695 583, India. \\ ${ }^{3}$ The Kerala State Council for Science, Technology and Environment (KSCSTE), Sasthra Bhavan, \\ Thiruvananthapuram 695004 , India. \\ *Corresponding author.e-mail: roxyms@gmail.com
}

Soil moisture is an important parameter of the earth's climate system. Regression model for estimation of soil moisture at various depths has been developed using the amount of moisture near the surface layer. The estimated values of soil moisture are tested with the measured moisture values and it is found that the estimations are comparable with the observations. The variation of soil thermal properties with the amount of moisture in isohyperthermic ultisols has been investigated at a tropical site in south Kerala for the year 2008. The soil temperatures at 0.05, 0.10, 0.20, 0.30, and $0.50 \mathrm{~m}$ depths and soil moisture at 0.05 and $0.10 \mathrm{~m}$ are measured using the hydrometeorological data acquisition system installed at the observational site. For soil water contents ranging between 11 and $42 \%$ in the soil layer of depth $0.05-0.10 \mathrm{~m}$, the mean values of the heat capacity, thermal diffusivity, thermal conductivity, and thermal admittance obtained were $2.2466 \times 10^{-6} \mathrm{Jm}^{-3} \mathrm{~K}^{-1}, 0.4238 \times 10^{-6} \mathrm{~m}^{2} \mathrm{~s}^{-1}, 0.9658 \mathrm{Wm}^{-1} \mathrm{~K}^{-1}$, $2.1517 \mathrm{Jm}^{-2} \mathrm{~s}^{-1 / 2} \mathrm{~K}^{-1}$, respectively. The magnitudes of the diurnal soil thermal parameters showed strong association with the levels of the water content. The thermal diffusivity was found to increase with the amount of soil moisture, up to about $22 \%$ of the volumetric water content, but fell as the water content further increases. Similar patterns of the soil moisture levels were noticeable both for the thermal conductivity and admittance.

\section{Introduction}

Studies have shown that soil moisture is the basic link between the hydrologic cycle and the energy budget of land surfaces. Therefore, soil moisture data is useful in many disciplines including agriculture, forest ecology, civil engineering, water resources, meteorology, and soil science (Wetzel and Woodward 1987). Soil respiration rates are affected by environmental factors such as soil moisture and soil temperature (Tamai 2010). The assessment of the productive soil moisture by physical measurement, especially in the deeper layers is very difficult. Moreover, taking samples from deeper layers is also laborious and time consuming. A large number of samples per unit area are required to be taken for obtaining a representative value of soil moisture. One of the ways to avoid these difficulties is to formulate some method of estimation of soil moisture at the deeper layers from parameters which can be measured easily.

The manner in which heat flows through the soil is of considerable importance in plant cultural practices in general. Specifically, it affects plant-root

Keywords. Soil moisture; thermal diffusivity; volumetric heat capacity; thermal conductivity; thermal admittance. 
activity with respect to the uptake of nutrients, water, etc., and in engineering uses of the soil. Heat conduction in soils is governed by thermal properties. Thermal properties of soil influence the partition of energy at the ground surface, and are related to the soil temperature and the transfer of heat and water across the ground surface (Nwadibia et al. 2010). The knowledge of thermal properties of soil is essential to study the surface energy and radiation budgets, to quantify surface temperature and heat storage required in agriculture, for germination rate, etc. Changes in ground temperature, thermal diffusivity and ground heat flux could be used as earthquake precursors (Rezapour et al. 2010). The thermal properties are strongly dependent on the variation with the water content of the soil. Soil water improves the thermal contact between the soil particles, and replaces air, which has 20 times lower thermal conductivity than water (Baver et al. 1972; Hanks and Ashcroft 1986).

The heat capacity per unit volume of soil is the quantity of heat needed to raise the temperature of a unit volume of soil by one degree Kelvin. Thermal conductivity of soil is the amount of heat transferred through a unit in unit time under a unit temperature gradient. It is a measure of the ability to conduct heat and is dependent upon the bulk density and the soil water content. Increasing soil bulk density increases the thermal conductivity. Abu-Hamdeh and Reeder (2000) found that the thermal conductivity increased considerably with increasing soil density and soil moisture content. They stated in their results that the thermal conductivity increased from 0.58 to 1.94 for sand, from 0.19 to 1.12 for sandy loam, from 0.29 to 0.76 for loam, and from 0.36 to $0.69 \mathrm{Wm}^{-1} \mathrm{~K}^{-1}$ for clay loam at densities from 1.23 to $1.59 \mathrm{~kg} \mathrm{~m}^{-3}$ and water contents from 1.4 to $21.2 \%$. The thermal diffusivity of soil, defined as the ratio of its heat conductivity and its volumetric heat capacity, is an important parameter for the determination of soil temperature distribution and heat flux in the soil. It depends on moisture content, composition, and texture of the soil. The thermal diffusivity of the soil controls the speed of the temperature waves and the depth of thermal influence of the active surface. Another related property of soil thermal characteristics is the thermal admittance, $\mu_{\mathrm{s}}$. The admittance is a measure of the ability of a soil surface to accept or release heat.

Wang et al. (2005) have analysed the relationship between the soil thermal parameters and soil moisture with the automatic weather station observation data. They found that the soil thermal conductivity increases as a power function of soil moisture content. The diffusivity first increases with increasing soil moisture, reaching its maximum at about 0.25 (volume per volume), then slowly decreases. Soil thermal capacity is rather stable for a wide range of soil moisture content. Liu et al. (2008) investigated the variations of the soil thermal parameters with soil moisture using a series of one-year continuous observation. They noted that the soil thermal conductivity increases as a power function of soil moisture, whereas the heat capacity changes are relatively small. The soil thermal diffusivity is found to increase with soil moisture and then to decrease after reaching the maximum at the soil moisture of 0.18 (volume per volume). Guan et al. (2009) found a relationship between the soil thermal properties and soil moisture. These studies concluded that soil thermal conductivity increases as a power function of soil moisture content. The thermal diffusivity first increases with increasing soil moisture, then decreases after reaching its maximum. The soil thermal capacity is found rather stable for a wide range of soil moisture content. Soil parameters are related to soil components, terrain, and geographic location. Soil thermal properties are key parameters controlling the energy and water cycles. Accurate parameterization of these properties will help to improve the accuracy of atmospheric models (Liu et al. 2008). Huang et al. (2008) have done a detailed study of the variations in the atmospheric parameters at Semiarid Climate and Environment Research Observatory over the Loess Plateau. A brief summary of the key measurements obtained at SACOL from May 2006 through May 2008 is presented in their paper. Their results conclude that accurate estimation of parameters like temperature, net radiation, sensible heat flux, latent heat flux, soil heat flux, etc., have a major role in improving the land surface and climate models.

In the present study, attempts have been made to estimate soil moisture at deeper depths from soil moisture at or near the surface layer by fitting suitable regression equations using hourly soil moisture data recorded at our experimental site. Thermal characteristics of soil greatly influence the energy budget of the plant environment. Heat stored in a soil depends upon its thermal characteristics and affects the evaporation that takes place at the surface. Here, the soil thermal properties such as soil thermal diffusivity, thermal capacity, thermal conductivity, and thermal admittance are calculated. The variation of thermal properties with degrees of wetness for a specific soil located in south India has been analysed.

\section{Site and data}

The study was conducted in bare soil at Astronomical Observatory $\left(76^{\circ} 57^{\prime} \mathrm{E}\right.$ longitude and $8^{\circ} 30^{\prime} \mathrm{N}$ 
latitude), University of Kerala, adjacent to India Meteorological Department, Thiruvananthapuram in south Kerala. Figure 1 shows the topography of the location of the experimental site. It is situated at about $64.31 \mathrm{~m}$ above mean sea level and nearly $8.4 \mathrm{~km}$ inland from coast. The climate of Kerala is tropical maritime and monsoonal in character. In fact the first burst of the southwest monsoon over the Indian subcontinent takes place over Kerala. The main rainy seasons in the state are southwest (SW) monsoon (June-September) and northeast (NE) monsoon (October and November). The pre-monsoon months (March-May) account for major thunderstorm activity in the state and winter months (December-February) are notable for minimum rainfall. The seasonwise rainfall over Kerala indicated that the major part of the annual rainfall is received during southwest monsoon followed by northeast monsoon. The least is seen in winter (Menon and Rajan 1989; Prasada Rao 2003). Monthly variation of meteorological parameters at the site during 2008 are given in figure 2, which shows respectively, the air temperature at screen height, soil temperature at $0.05 \mathrm{~m}$, rainfall, and relative humidity. From the figure, it is seen that total rainfall is high during NE monsoon. Rainfall is abundant with rain for nearly 10 months of the year from March to December. There is some rain even in the remaining two months. Heating and cooling of soil and air during summer and monsoon seasons causes annual variations of temperatures. It is seen from figure 2 that air and soil temperatures are high during pre-monsoon and winter periods. Relative humidity is found to be high during SW and NE monsoons. The mean soil and air temperatures are greater than $25^{\circ} \mathrm{C}$ and mean relative humidity is greater than $70 \%$. Thus the climate at the site is tropical in nature.

Kerala comes under isohyperthermic temperature regime (Chacko and Renuka 2008) which means that annual soil temperature is $22^{\circ} \mathrm{C}$ or higher and mean soil temperature of June-August and December-February differ by less than $5^{\circ} \mathrm{C}$ at a depth of $50 \mathrm{~cm}$ or at lithic or paralithic contact whichever is shallower. The colour of the soil at the experimental site varies from

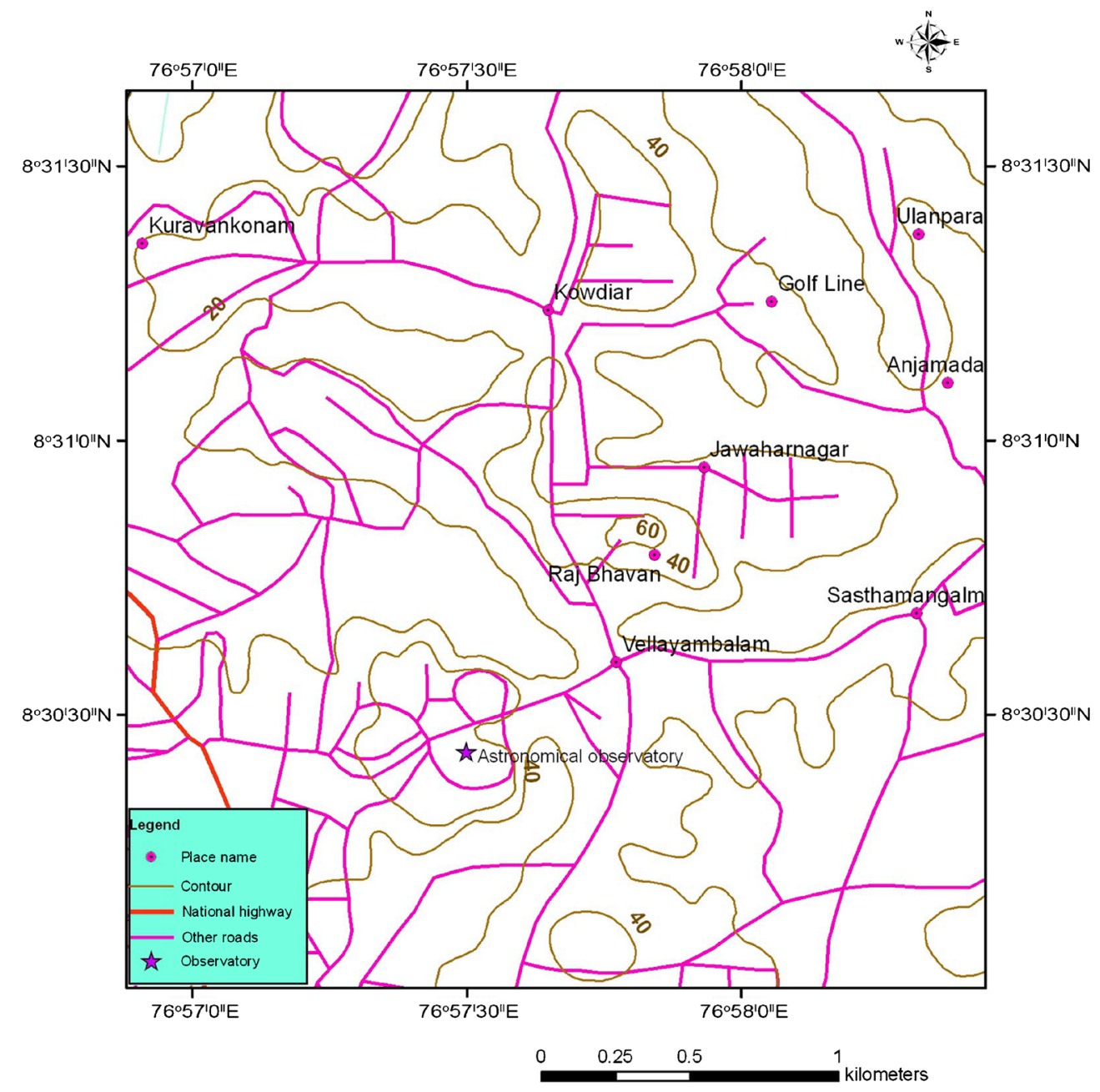

Figure 1. The topography of the location of the experimental site. The location is represented as a star for reference. 

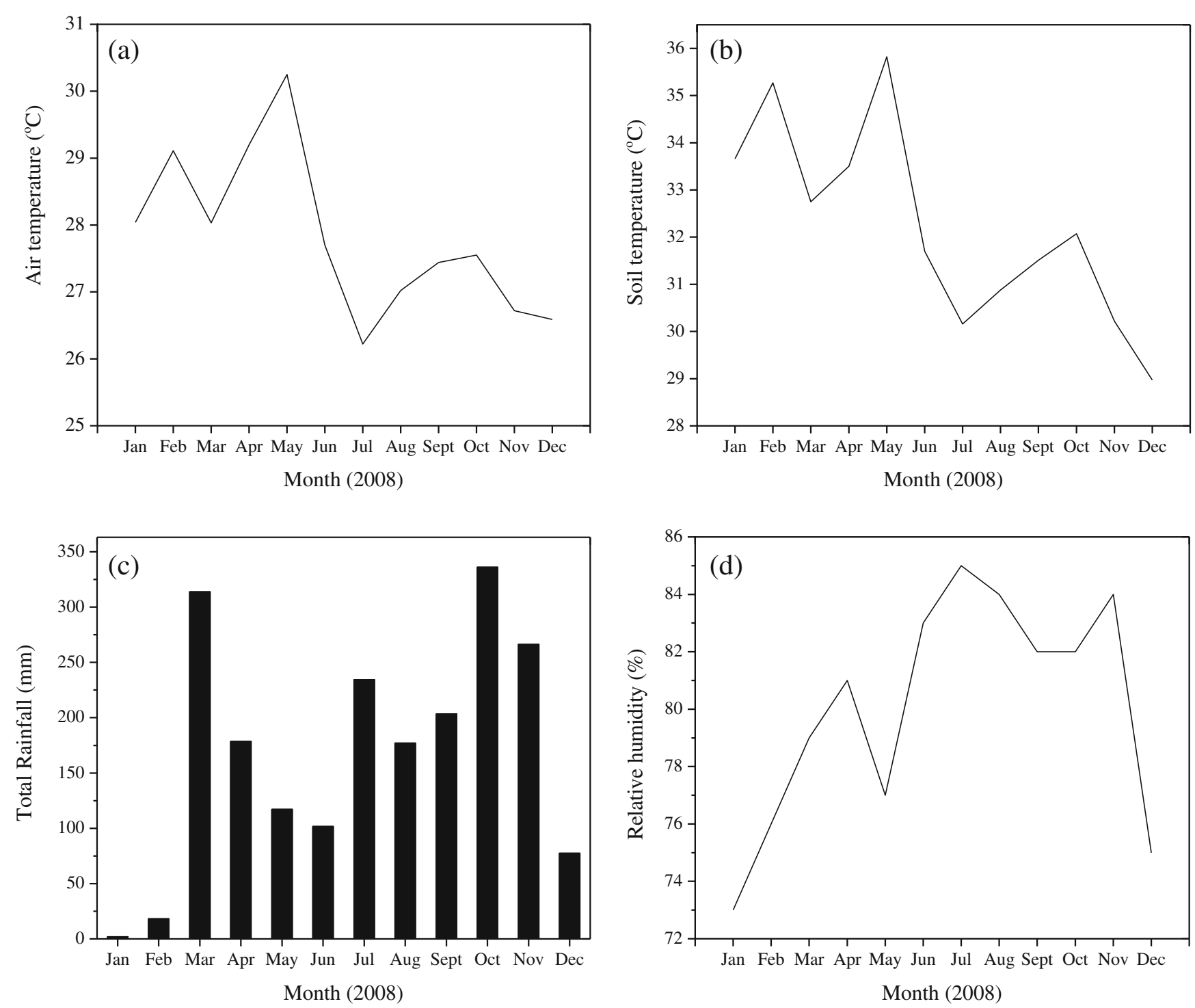

Figure 2. Monthly mean of meteorological parameters at the site during 2008. (a) Air temperature at screen height, (b) soil temperature at $0.05 \mathrm{~m}$ depth, (c) rainfall, and (d) relative humidity.

dark brown to dark reddish brown as we go to the deeper layers. Correspondingly the soil texture varies from gravelly sandy loam to gravelly clay loam. The clay increase in subsurface layers qualifies these soils to be placed under ultisols. The experimental site belongs to soils of laterite landscape developed under tropical climate with alternate wet and dry seasons. The experimental site is the meteorological representative of the area in which it is located. The atmospheric variables measured on the site are typical of the area.

The hourly soil moisture measured at depths of $0.05,0.10,0.20,0.30$, and $0.50 \mathrm{~m}$ for the 2-year period, 2008 and 2009, are considered for the estimation of soil moisture at different depths and the same for the year 2008 is used to study the soil thermal characteristics. Unfortunately data for the month of April 2008 is missing due to technical reasons. The sensing element for soil temperatures is $\mathrm{P}-\mathrm{N}$ junction semiconductor with fast response designed for continuous and long term measurements at soil depth. It is encased inside a stainless steel cover filled with silicon for better thermal conductivity and also to withstand the high geo-static pressure and rough handling in the field. A principle based on soil impedance is employed to sense the soil moisture directly from soil depths. Here the sensor is excited with sinusoidal signals of a selected and fixed frequency for eliminating electrical polarization and hence to obtain a long term consistency in performance. The sensor associated with its signal conditioning, processed with embedded software eliminates the inherent non-linearity in its performance (Sivadas 2007). The sensors installed at different depths 
and heights from the soil surface measure temperature between 0 and $60^{\circ} \mathrm{C}$. The resolution of soil temperature data is $0.1^{\circ} \mathrm{C}$ with accuracy of $\pm 0.2^{\circ} \mathrm{C}$. Analog-to-digital converter (ADC) with 12 bits resolution, $1000 \mathrm{~KB}$ of non-volatile memory, built-in real time clock, suitable for single analogous channel for multiplexing up to 256 channels, RS232 port for feeding data to computer is used for data storage. Software supports downloading data to computer and displaying data of all channels in real time. The instruments have been tested and calibrated at regular intervals by the manufacturers (Environmental Measurements and Controls, Cochin). The data is compared with imported and good performance types available with Central Institute of Fisheries Technology (CIFT), Cochin and Rubber Research Institute of India (RRII), Kottayam. All the sensors have good linearity and sensitivity which is approved by the calibration certificate of IMD, Pune. The relative humidity and rainfall were collected from IMD, Thiruvananthapuram.

\section{Method}

\subsection{Soil moisture}

The equation suggested to estimate soil moisture at deeper depth from that at or near the surface layer was of the form (Biswas and Dasgupta 1979)

$$
S=A\left(d-d_{0}\right)+S_{0}\left[1+B\left(d-d_{0}\right)^{2}\right]+S_{c}
$$

where $S$ is the soil moisture at depth $d ; S_{0}$ the soil moisture at or near the surface layer at depth $d_{0} ; A, B$ and $S_{c}$ are constants. $S_{0}, d$ and $d_{0}$ being known, $S$ was estimated from them.

A condition that this equation has to satisfy is that when $d$ equals $d_{0}, S$ should be equal to $S_{c}$. If the constant $S_{0}$ is taken at zero, equation (1) satisfies this condition. When equation (1) was fitted with $S_{c}$ equal to zero, it was observed that in most of the cases the estimated soil moisture for all the depths showed a more or less constant deviation from the observed values. This constant deviation was considered to be a characteristic of the soil and hence constant $S_{c}$ was introduced and it is equal to a constant value other than zero when $d$ is different from $d_{0}$ and equal to zero when $d$ is equal to $d_{0}$.

Putting $\gamma=S-S_{c}, X_{1}=\left(d-d_{0}\right)$ and $X_{2}=$ $S_{0}\left(d-d_{0}\right)^{2}$, the equation (1) can be rewritten

$$
\gamma=S_{c}+A X_{1}+B X_{2} .
$$

This equation was fitted to the soil moisture data by the method of multiple regression and the constants $S_{c}, A$ and $B$ were determined.

\subsection{Thermal diffusivity}

The heating of the earth's surface by the sun during the day, followed by cooling during night, results in a diurnal temperature wave with a time period of 24 hours. The equation for conductive heat transfer in a one-dimensional isotropic medium is (Kaushik et al. 1965)

$$
\frac{\partial T}{\partial t}=k_{s} \frac{\partial^{2} T}{\partial z^{2}}
$$

where $T$ is the soil temperature, $k_{s}$ is the soil thermal diffusivity, $t$ the time and $z$ the depth. The thermal diffusivity can be estimated from measurements of amplitude decrement and phase difference of the temperature waves between various depths in the ground. The solution of equation (3) yields the amplitude $A$ of the temperature wave at any depth $z$ given by

$$
A=A_{0} \exp \left[-\sqrt{\frac{\omega}{2 k_{s}}} z\right]
$$

where $A_{0}$ is the amplitude of the thermal wave at the surface and $\omega$ is the angular velocity of earth's rotation $\left(7.292 \times 10^{-5} \mathrm{rad} / \mathrm{sec}\right)$. Thus, it follows from equation (4) that the amplitude equation for calculating thermal diffusivity is given by

$$
k_{s}=\frac{\omega}{2}\left[\frac{z}{\ln \left(A / A_{0}\right)}\right]^{2} .
$$

\subsection{Volumetric heat capacity}

The volumetric heat capacity $\left(C_{s}\right)$ of the soil, which is dependent on volumetric moisture content $(\eta)$, is computed using (Sellers 1972)

$$
C_{s}=\left(1-\eta_{s}\right) C_{s i}+\eta C_{w}
$$

where $\eta$ is the volumetric moisture content, $\eta_{s}$ is the saturated value of $\eta, C_{s i}$ is the volumetric heat capacity of dry soil type ' $i$ ' and $C_{w}$ is the volumetric heat capacity for water. The equation (6), in fact, is a weighting of the contribution to $C_{s}$ from the dry soil and the water present in the soil (neglecting the contribution of air). In equation (6) the values of $\eta_{s}, C_{s i}$ and $C_{w}$ taken from Garratt (1992) are used.

\subsection{Thermal conductivity}

Thermal conductivity $\left(K_{s}\right)$ is the product of volumetric heat capacity $\left(C_{s}\right)$ of the soil and thermal diffusivity $\left(k_{s}\right)$ and is given as:

$$
K_{s}=C_{s} k_{s} \text {. }
$$




\subsection{Thermal admittance}

Thermal admittance is given by

$$
\mu_{s}=C_{s} K_{s}^{-1 / 2}=\left(k_{s} C_{s}^{-1}\right)^{-1 / 2} .
$$

It is to be noted that the ratio of soil thermal admittance to that of the surrounding air determines the sharing of sensible heat between the soil and the atmosphere.

\section{Results and discussion}

\subsection{Analysis of soil moisture}

Having reliable information on the spatial and temporal variability of soil-moisture is a key to many practical and scientific problems (Peled et al. 2010). Knowledge of the pattern of soil moisture distribution and its accumulation at various depths is vital for designing effective agronomic practices. Soil water content in the root zone depth is an important factor in the evapotranspiration measurement, irrigation scheduling, crop water stress monitoring, and also an input data in various crop simulation models. Studies on some of the characteristics of soil moisture variations in the surface layer and the movement of moisture through the soil have been made by Ramdas and Mallik (1942), Baier and Robertson (1966) and Baier (1969). Biswas (1978) studied the fluctuations of soil moisture at the different layers in relation to rainfall for a few stations.

Attempts have been made in this study to estimate soil moisture at deeper depths from soil moisture at or near the surface layer by fitting suitable regression equations using the recorded soil moisture data at the experimental site.
When plotted as a graph, the soil moisture values show the following features:

(1) The variation of soil moisture at a particular depth was more or less linear with the soil moisture near the surface layer (figure 3).

(2) The variation of soil moisture with depth was curvilinear, but approached linearity with decrease in soil moisture near the surface layer (figure 4) to quite low values.

Incorporating these two features, the suggested equation (1) is found to be suitable to estimate soil moisture at deeper depths from that at or near the surface layer.

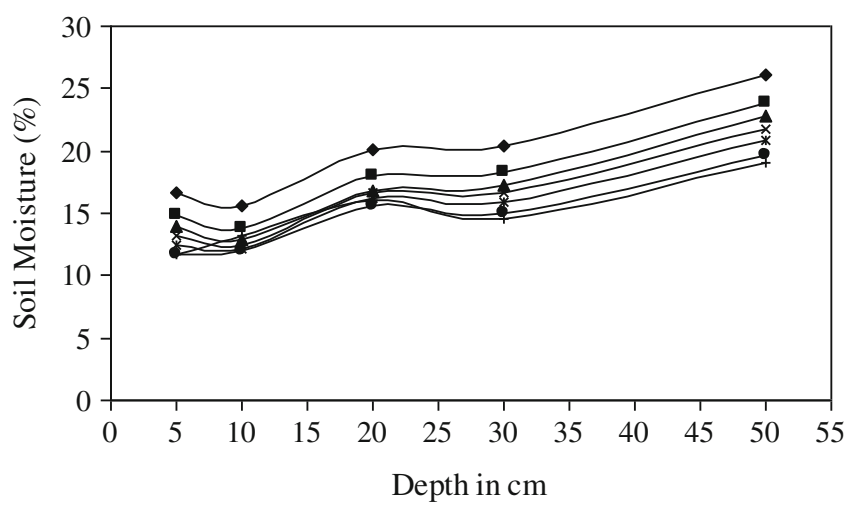

Figure 4. Variation of soil moisture with depth.

Table 1. Constants in regression equation (1) and coefficient of determination $(C D)$ between soil moisture.

\begin{tabular}{lcccccc}
\hline & & & \multicolumn{4}{c}{ C D for depths } \\
\cline { 4 - 8 } Sc & A & B & $0.10 \mathrm{~m}$ & $0.20 \mathrm{~m}$ & $0.30 \mathrm{~m}$ & $0.50 \mathrm{~m}$ \\
\hline-0.9919 & 32.38 & -1.2114 & 0.82 & 0.99 & 0.91 & 0.7 \\
\hline
\end{tabular}

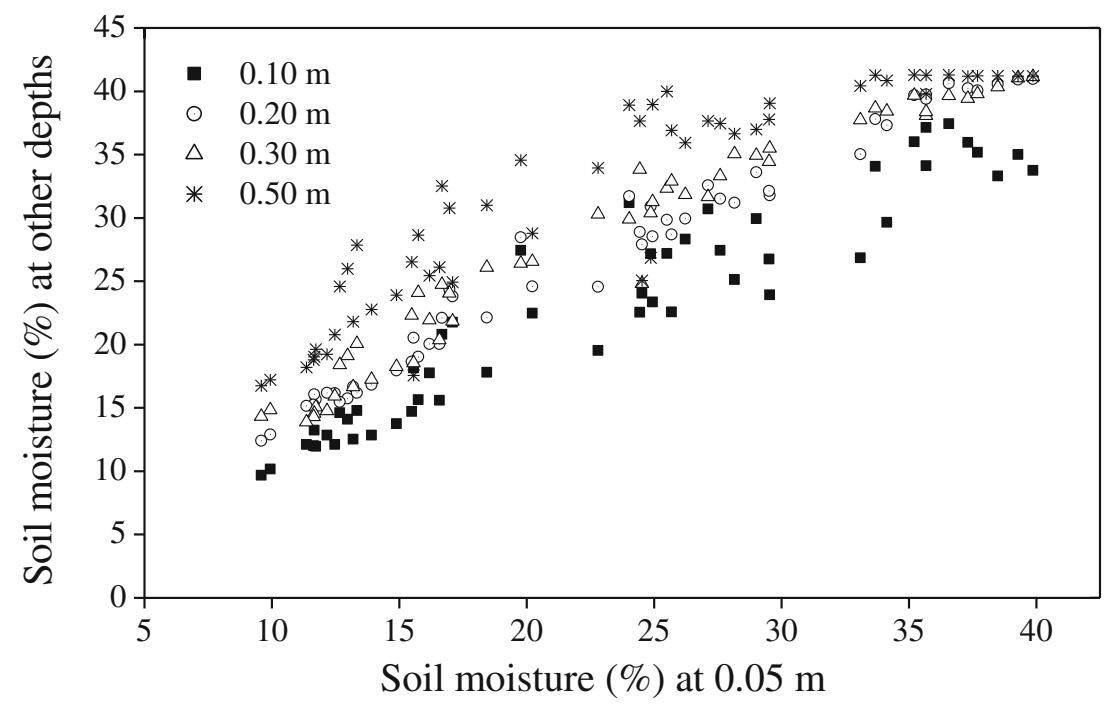

Figure 3. Soil moisture (\%) at $0.05 \mathrm{~m}$ depth versus soil moisture (\%) at other depths. 

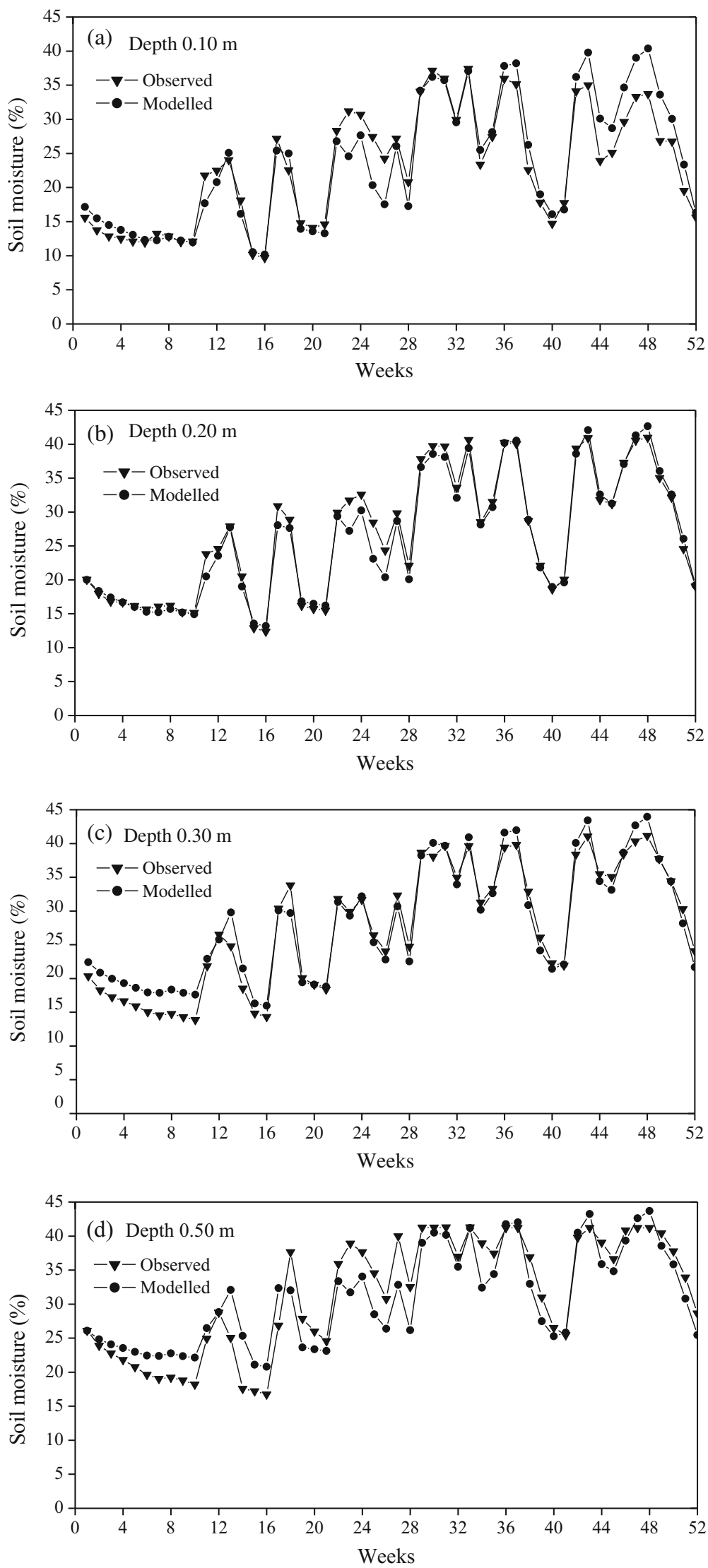

Figure 5. (a-d) Observed and modelled soil moisture. 


\subsection{Estimation of soil moisture at deeper depths}

Obtaining the values of $A, B$ and $S_{c}$ (table 1) soil moisture for all the other depths were estimated from the soil moisture at the topmost layer. The estimations were done on the weekly averaged data. Figure 5(a-d) shows the estimated and observed soil moisture at depths $0.10,0.20,0.30$, and 0.50 $\mathrm{m}$ under bare soil during the years 2008 and 2009 . The errors of estimation (observed minus estimated soil moisture expressed as percent of observed values) subsequently computed showed (figure 6a-d) that estimates were considerably good. Only in few cases, errors were more than $20 \%$ of the observed values. The high coefficients of determination also reveal the same (table 1). The CAgM of WMO has indicated that if the soil moisture at different depths at a place is measured by different methods, a variation of more than $15 \%$ is possible. Considering this situation the developed equation for our station may be conveniently used to estimate the soil moisture of deeper layers from that of the surface layer.

\subsection{Variation of thermal properties with water content}

The mechanisms of heat transfer in soil are, in order of importance (De Vries and Afgan 1975) conduction, convection, and radiation. Conduction occurs throughout the soil, but the main flow of heat is through the solid and liquid parts. Convection in the usual sense is at most times negligible, with the exception of rapid infiltration of water. This does not hold for the transport of latent heat by water vapour, which may contribute greatly to the heat transfer in the gas filled pores. Heat transfer due to radiation is only of importance in dry soils at high temperatures and within large pores.

Water content has a pronounced effect on volumetric heat capacity, thermal conductivity, and therefore on other thermal properties. The variation of the following thermal properties: (1) thermal diffusivity, (2) heat capacity, (3) thermal conductivity and (4) thermal admittance, with the soil water content in the layer $0.05-0.10 \mathrm{~m}$ are discussed on a day-to-day basis for the period 1 January to 31 December 2008. From figure 7, we can see that the thermal diffusivity increases with increasing soil moisture during the winter (December-February) and early pre-monsoon (up to March 15). These are dry days with moisture content less than $22 \%$. When moisture is $22 \%$, the diffusivity increased to about $0.86 \times 10^{-6} \mathrm{~m}^{2} \mathrm{~s}^{-1}$ (88th day). The lowest moisture during this season is $11.51 \%$ with diffusivity $0.20 \times 10^{-6} \mathrm{~m}^{2} \mathrm{~s}^{-1}$ (38th day). Thus, below $22 \%$ of moisture content, soil thermal diffusivity shows a positive correlation with moisture.

During the monsoon seasons, the moisture content increases up to $42 \%$. Here, the thermal diffusivity shows a tendency to decrease with increase in soil water contents. For instance, the diffusivity is found as $0.17 \times 10^{-6} \mathrm{~m}^{2} \mathrm{~s}^{-1}$ when moisture content is $42 \%$ (78th day) and it is $0.65 \times 10^{-6} \mathrm{~m}^{2} \mathrm{~s}^{-1}$ when moisture content is $26.17 \%$ (304th day). This is understandable because Oke (1978) suggested that adding soil moisture to a dry soil initially results in an increase in thermal diffusivity and it begins to decline when moisture content exceeds $20 \%$ by volume.

Figure 8 shows the variation of the soil thermal conductivity together with the soil water content during the same study period, i.e., from January 1-December 31, 2008. It can be observed from this figure that the soil conductivity varies with soil moisture content. The thermal conductivity rose in values as the water content increased.

We have also noticed that there is a limiting value (peak) to the thermal conductivity at about $22 \%$ of soil water content, beyond which the conductivity falls in values. Thus, both the thermal diffusivity and conductivity showed a similar variation with the soil moisture content (figure $9 \mathrm{a}-\mathrm{d}$ ). Water and air are the soil constituents which vary considerably on a daily basis but since water has about 20 times the thermal conductivity of air, it is more influential on the soil thermal properties. Presence of water films at points of contact between particles not only improves the thermal contact but also replaces air in the soil pore space (Baver et al. 1972; Hanks and Ashcroft 1986). From the figure, one can see that the distribution of soil thermal diffusivity is scattered. The possible reason is that soil thermal diffusivity depends not only on soil moisture but also on other factors like dry density, mineral composition, temperature, texture, change in volumetric air, and soil phase content (Hillel 1982; Peters-Lidard et al. 1998; Tyson et al. 2001; Sen et al. 2007). The dependence of soil thermal diffusivity on soil water content has a complex and nonlinear character (Arkhangel'skaya 2009). The scattered plot between thermal diffusivity and soil moisture is due to the fact that the field soils usually exhibit changing volumetric water content and bulk density with depth and time. In the present study, amplitude method has been used to find the soil thermal diffusivity in the field, but it has suffered from limitations due to the assumption of homogeneous soil properties.

Padmanabhamurty et al. (1998) examined how thermal diffusivity varies with different characteristics of soil like moisture, texture, etc. They found that for a clay soil, average values of thermal diffusivity calculated by different methods for the sites 

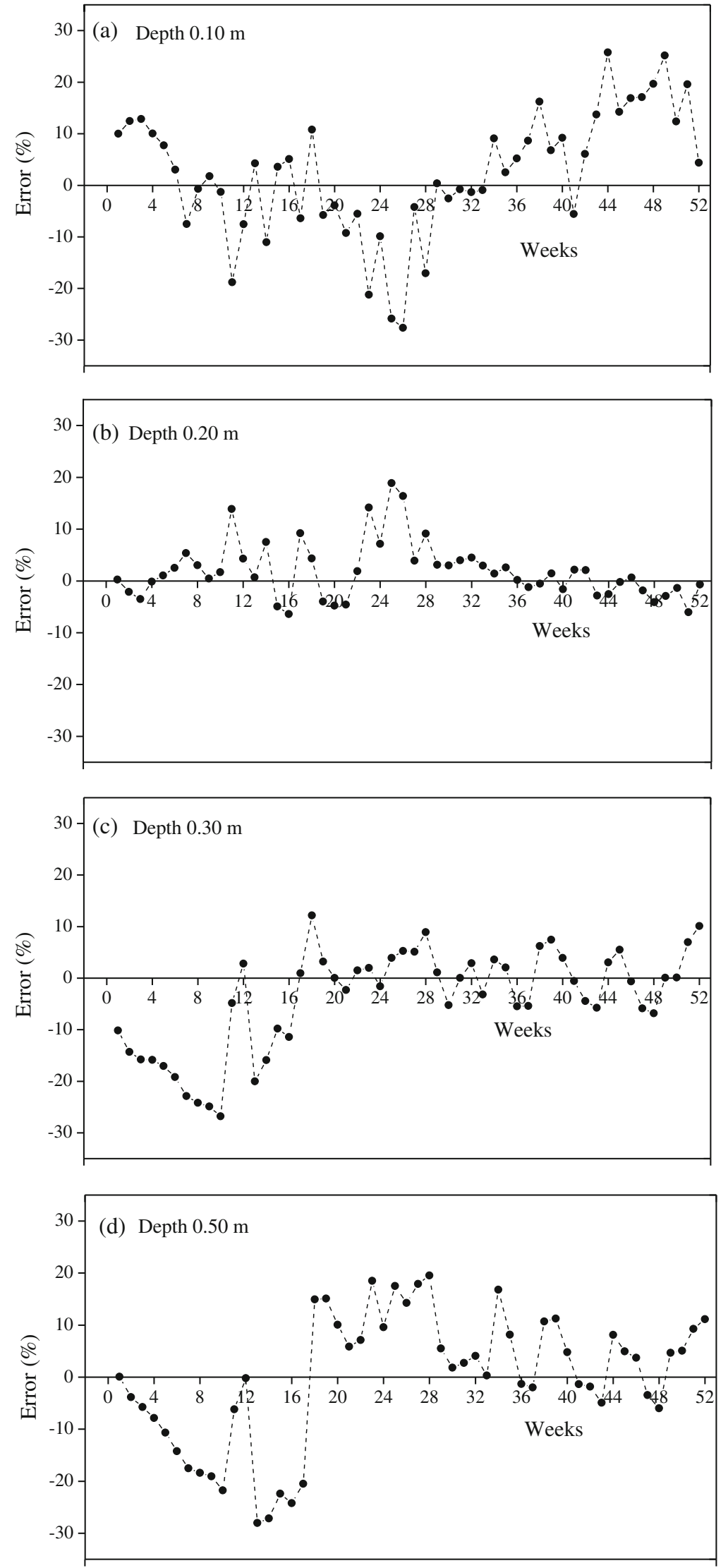

Figure 6. (a-d) Errors of estimation expressed as percent of observed values. 


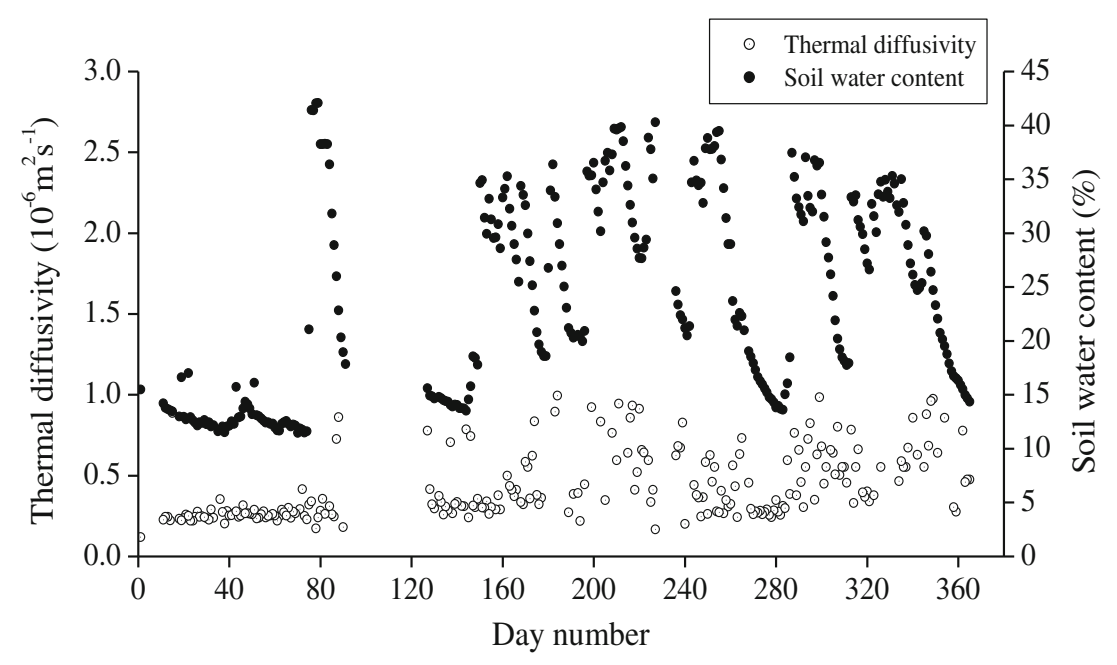

Figure 7. Thermal diffusivity with soil water content in the soil layer $0.05-0.10 \mathrm{~m}$ from January $1-$ December 312008 at the site.

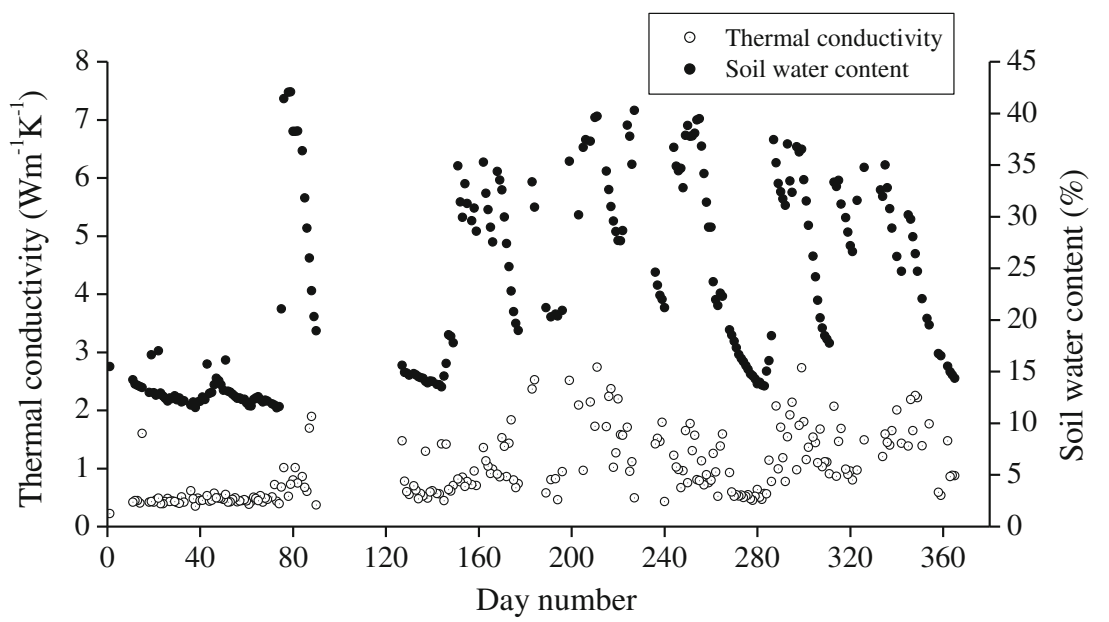

Figure 8. Thermal conductivity with soil water content in the soil layer $0.05-0.10 \mathrm{~m}$ from January $1-$ December 312008 at the site.

Khanda and Arnej are $0.287 \times 10^{-6} \mathrm{~m}^{2} \mathrm{~s}^{-1}$ (volumetric moisture content, $\eta=0.248 \mathrm{~m}^{3} \mathrm{~m}^{-3}$ ) and $0.304 \times 10^{-6} \mathrm{~m}^{2} \mathrm{~s}^{-1}\left(\eta=0.230 \mathrm{~m}^{3} \mathrm{~m}^{-3}\right)$, respectively. For the loamy sand soil at Derol and Anand, the values of thermal diffusivity are $0.677 \times 10^{-6}$ $\mathrm{m}^{2} \mathrm{~s}^{-1}\left(\eta=0.133 \mathrm{~m}^{3} \mathrm{~m}^{-3}\right)$ and $0.508 \times 10^{-6} \mathrm{~m}^{2} \mathrm{~s}^{-1}$ $\left(\eta=0.120 \mathrm{~m}^{3} \mathrm{~m}^{-3}\right)$, respectively. For the clay loam soil at Sanand, the thermal diffusivity value is $0.591 \times 10^{-6} \mathrm{~m}^{2} \mathrm{~s}^{-1}\left(\eta=0.069 \mathrm{~m}^{3} \mathrm{~m}^{-3}\right)$.

In another study, Anandakumar et al. (2001) investigated the thermal properties at two sites at Kalpakam, located on the southeast coast of India. The soil composition at location 1 is a mixture of clay, sand, and organic materials, whereas at location 2 , the clay content is dominant. They reported that the value of soil thermal diffusivity at location 2 shows a decreasing trend due to the gradual day by day drying up of the soil layer. The value obtained for the day corresponding to wet soil surface is more than two times larger than that for the dry days. Tessy Chacko and Renuka (2002) calculated the thermal diffusivity of laterite soil at Kariavattom of south Kerala. The average value of thermal diffusivity of the soil calculated by range method for a wet $\left(\eta=0.32 \mathrm{~m}^{3} \mathrm{~m}^{-3}\right)$ and dry day $\left(\eta=0.13 \mathrm{~m}^{3} \mathrm{~m}^{-3}\right)$ are $0.633 \times 10^{-6}$ and $0.336 \times 10^{-6}$ $\mathrm{m}^{2} \mathrm{~s}^{-1}$ and by lag method are $0.668 \times 10^{-6}$ and $0.307 \times 10^{-6} \mathrm{~m}^{2} \mathrm{~s}^{-1}$, respectively. All these results show the difference in thermal diffusivities of wet and dry soil surfaces.

Soil water content plays an important role in determining soil thermal properties. The conduction through the soil is largely electrolytic. When the soil moisture increases, the thermal conductivity rises, because water is a good conductor. It is known that the thermal diffusivity is directly proportional to thermal conductivity. So when the moisture increases, the thermal diffusivity also 

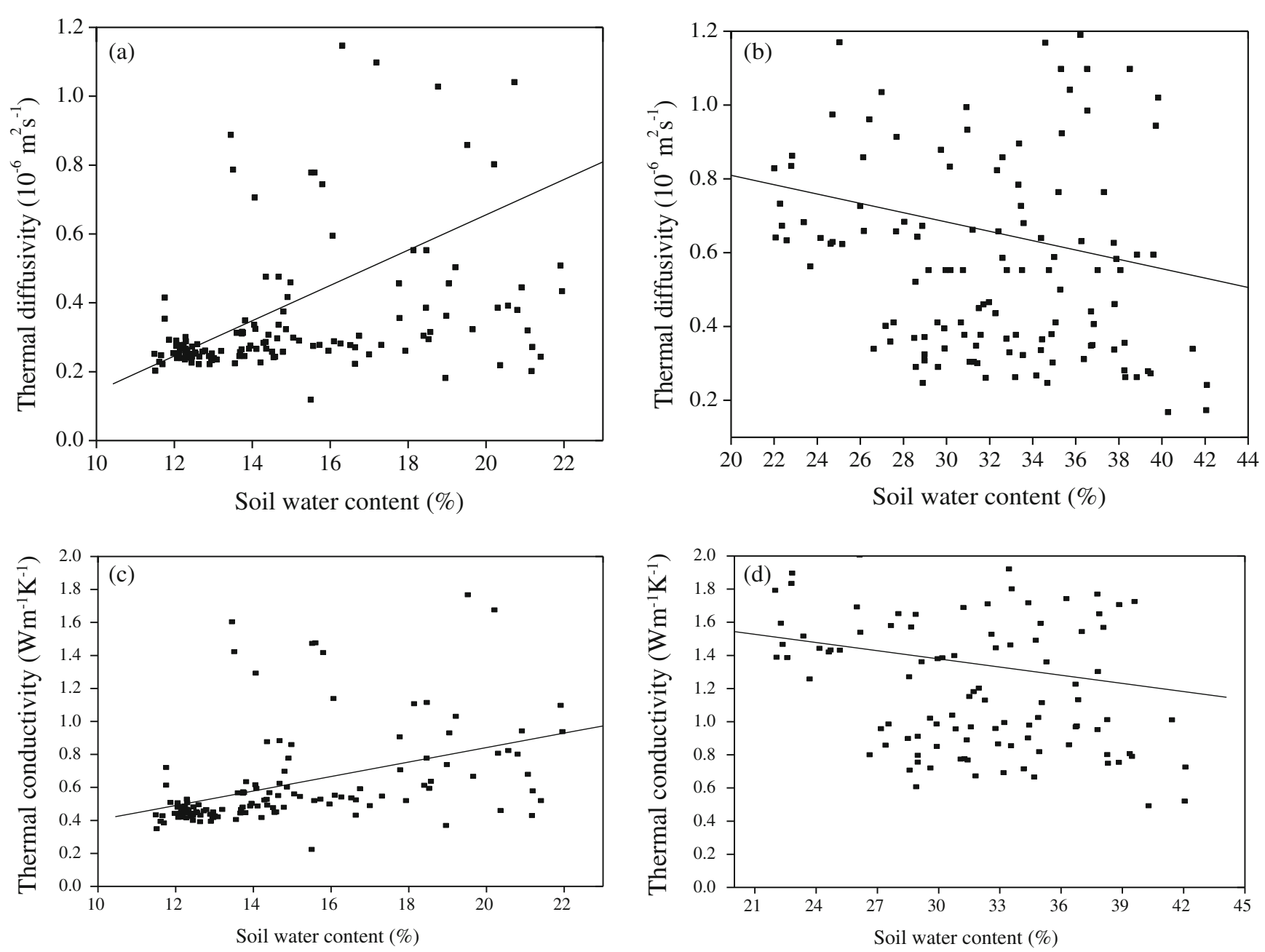

Figure 9. (a-d) Scatter plot of thermal diffusivity with water content $(\mathbf{a})<20 \%,(\mathbf{b})>20 \%$ and thermal conductivity with water content, $(\mathbf{c})<20 \%$, and $(\mathbf{d})>20 \%$.

increases up to some limited soil water content. The maximum thermal diffusivity occurs at medium moisture values due to the added effect of vapour phase movement of moisture and heat transfer (Lamba and Sunita Bhandari 1998). Oke (1978) suggested that adding soil moisture to a dry soil initially results in an increase in thermal diffusivity and it begins to decline when moisture content exceeds $20 \%$ by volume. Also, the organic matter does not transfer heat as readily as mineral soil and lowers the thermal diffusivity.

The variation of the heat capacity and soil water content for the same period, i.e., from January 1 -December 31, 2008 is shown in figure 10. The heat capacity is observed to be positively correlated with the degree of soil wetness. For instance, between the 139th and 147th day, the soil water content increased from about $14 \%$ to $18.5 \%$ and correspondingly, the heat capacity value estimated rose from $1.8 \times 10^{-6}$ to $2.0 \times 10^{-6} \mathrm{Jm}^{-3} \mathrm{~K}^{-1}$. Also from this same figure, between 263rd day and 283rd day, when the soil water content reduced from about $21.4 \%$ to $13.6 \%$, the value of the heat capacity reduced from $2.1 \times 10^{-6}$ to $1.8 \times 10^{-6}$ $\mathrm{Jm}^{-3} \mathrm{~K}^{-1}$. Thus, a linear relationship between the soil heat capacity and the soil water content is established.

In order to investigate the dependence of thermal admittance on soil moisture, thermal admittance and soil moisture is plotted for the study period. Figure 11 shows the variation of the thermal admittance with the soil water content for the same period, i.e., from January 1-December 31, 2008. It can be seen that the thermal admittance varies significantly with soil moisture content. During the period between 268th and 281st day when the soil water content reduced from about $19 \%$ to $14 \%$ the thermal admittance decreased from 1.9 to $1.4 \mathrm{Jm}^{-2} \mathrm{~s}^{-1 / 2} \mathrm{~K}^{-1}$. Between 33rd and 47th day when the soil moisture content increases from $12 \%$ to $14.5 \%$, the thermal admittance increased from 1.13 to $1.29 \mathrm{Jm}^{-2} \mathrm{~s}^{-1 / 2} \mathrm{~K}^{-1}$. This positive correlation is not visible when the moisture content is greater than about $22 \%$. Thus 


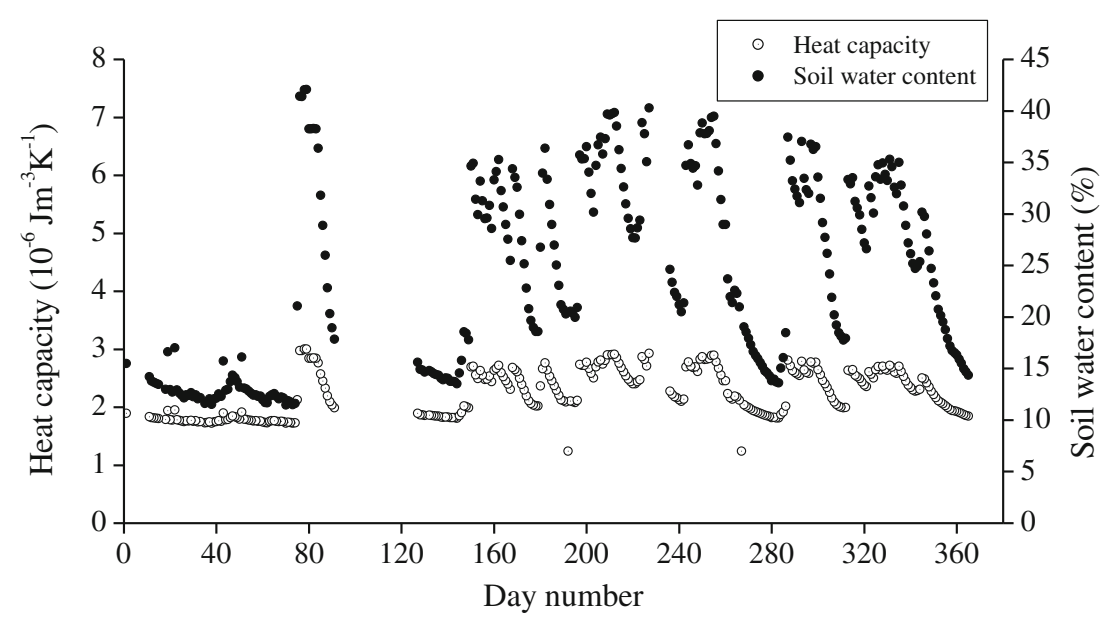

Figure 10. Heat capacity with the soil water content in the soil layer $0.05-0.10 \mathrm{~m}$.

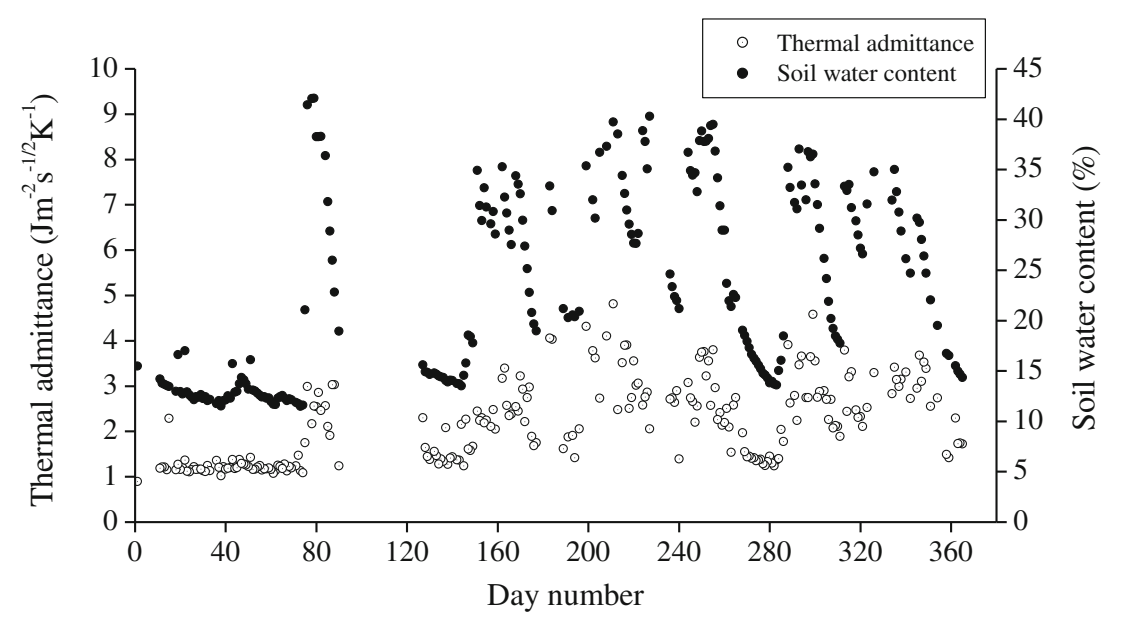

Figure 11. Thermal admittance with the soil water content in the soil layer $0.05-0.10 \mathrm{~m}$.

for a certain level of soil wetness, the thermal admittance increases with the wetness but with further increase in soil wetness it reduces.

Heat and moisture exchanges between the ground surface and the atmosphere are frequently dominant driving mechanisms for meso-scale circulations. Coupled models of heat and moisture transport in soils require information about soil thermal properties, which are used to determine temperature profile and heat flux in the soil. The soil thermal properties, due to their dependency on the soil moisture content, vary both in space and in time causing two types of heterogeneity (Verhoef et al. 1996). A meso-scale heterogeneity can be induced by spatially variable rainfall, which influences these properties through changes in soil moisture content on a scale of several kilometers. Second, heterogeneity on the micro-scale depends on the conditions of the surface, that is, bare or covered with vegetation. This influences the underlying soil by shading it homogeneously or not, with influence on the soil moisture, and thus the soil thermal properties.

\subsection{Time lag of thermal wave}

The soil surface is the most important source of variation in soil temperature. Solar radiation reaching the soil surface is reflected in part, the remainder being used to heat the soil and the air and to evaporate water. When the soil surface is heated, energy is transported vertically by conduction through the soil by the downward thermal gradient. At night the thermal gradient near the surface reverses, and heat is returned to the surface to be radiated, lost by conduction to the air or used in evaporation from the soil surface. Deeper in the soil, the temperature distribution takes the form of a wave which propagates downwards, being attenuated rapidly.

Experimental determination of soil thermal diffusivity is not easy in the field; hence it has 
been determined using the measured soil temperatures. Damping depth approach followed by Van Wijk (1965) is one of the methods to find the value of thermal diffusivity. In a homogeneous soil, lag in maximum or minimum temperature and phase angle of the fundamental temperature wave should respectively increase and decrease linearly, and the logarithm of the temperature amplitude should decrease linearly with soil depth (Bocock and Adamson 1982).

From the plot of the time lag between two successive crests of the thermal wave and the soil depth (phase method), the soil temperature data over the whole period of field observation showed a linear variation as in figure $12(\mathrm{a})$.

The ground surface starts heating at about sunrise and the rate of heating is high at noon. When the wave penetrates slowly into ground, it gets damped. There is a tendency for the amplitude to decrease with depth. During the day, the intense solar radiation is absorbed by the soil which warms the ground surface more than the layers beneath.
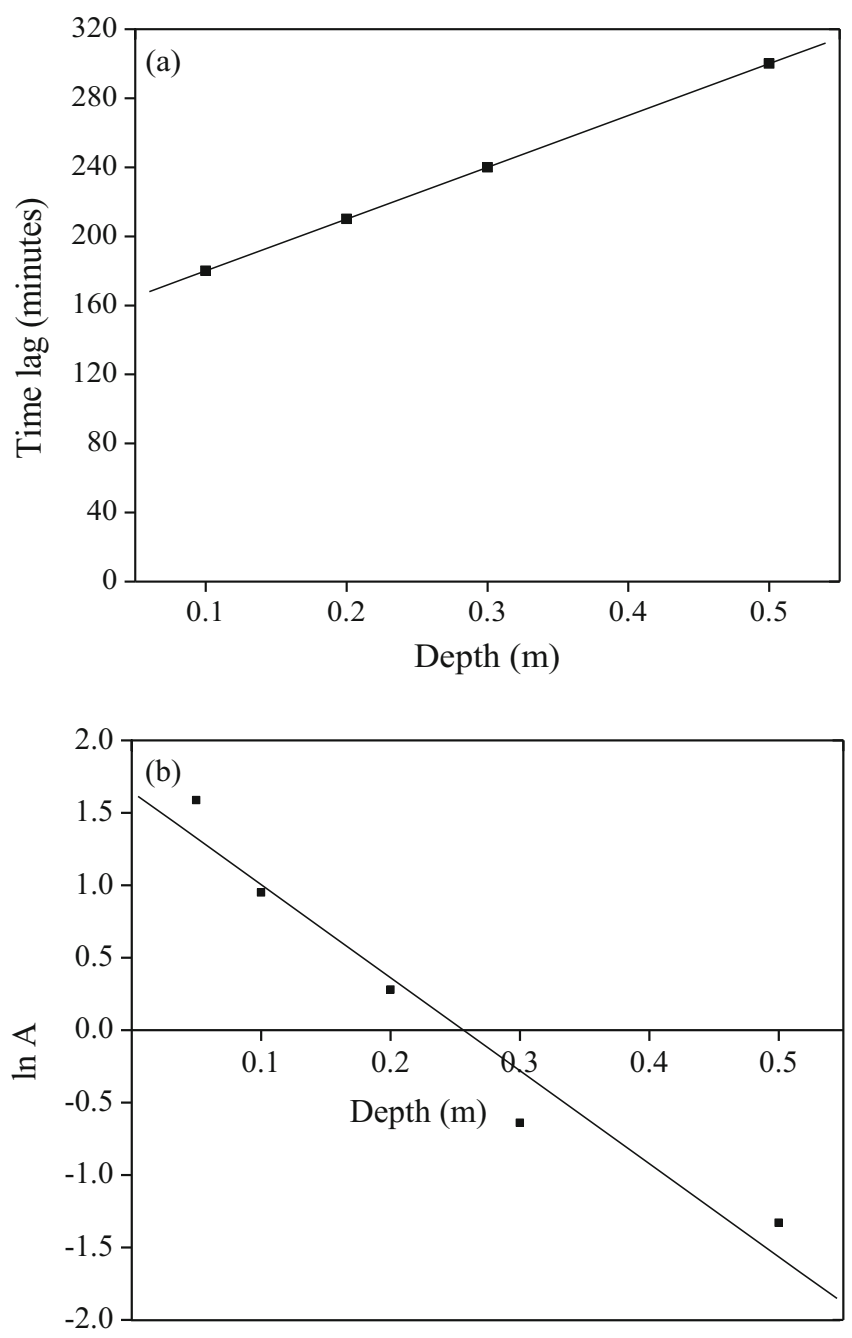

Figure 12. (a) Plot of the time lag against the soil depth at the site and (b) same as (a) but for wave amplitude.
The time lag of the thermal wave increases proportionately with depth and it keeps the soil warm. It naturally reverses the flow of heat upward towards the surface influencing the energy balance across the soil-air interface.

\subsection{Damping depth}

The damping depth is indicative of the extent of penetration of the temperature wave into the soil profile. It is the soil depth at which the amplitude of the sinusoidal temperature wave is equal to the reciprocal of the base of natural logarithms, $e$ times the amplitude of the corresponding wave at the soil surface.

The slope of the graph in figure 12(a) yielded the damping depth, $D=0.0785 \mathrm{~m}$. From this value, we calculated the layer averaged soil thermal diffusivity from the relation, $k_{s}=D^{2} \omega / 2$ where $\omega$ is $2 \pi$ the frequency of soil temperature. We have obtained thermal diffusivity of $0.4476 \times 10^{-6} \mathrm{~m}^{2} \mathrm{~s}^{-1}$. Similarly in figure $12(\mathrm{~b})$, the logarithm of the wave amplitude is shown to vary linearly with the soil depth. The second graph gave damping depth $D=$ $0.0637 \mathrm{~m}$. Using this value, the thermal diffusivity is obtained as $k_{s}=0.2947 \times 10^{-6} \mathrm{~m}^{2} \mathrm{~s}^{-1}$. The difference between the two values is attributable to the fact that due to the presence of higher harmonics in the diurnal thermal wave the time lag method tends to overestimate (Canuffo and Bernadi 1982).

\section{Conclusions}

- Information on soil moisture in different layers for agricultural planning and irrigation management, is undoubtedly the most important feature. The measurements of soil moisture at deeper layers are very difficult especially in heavy soils. Regression models for estimation of soil moisture at various depths have been developed using the amount of moisture near the surface layer. The estimated values are compared with observed ones. The errors of estimation are computed and it is found that the estimations are comparable with the observations.

- The values of the soil thermal properties (thermal diffusivity, heat capacity, thermal conductivity, and thermal admittance) obtained from January 1 -December 31,2008 , have shown a strong relation with the degree of soil wetness for the iso-hyperthermic ultisols. There is a positive linear correlation with the volumetric water content for all the parameters. However, we have found that there is a ceiling value of about $22 \%$ soil water content beyond which the thermal diffusivity falls in magnitude. Similar trends are 
obtained for thermal conductivity and thermal admittance.

- For the soil layer, 0.05-0.10 m, the mean values of the heat capacity, thermal diffusivity, thermal conductivity, and thermal admittance determined were $2.2466 \times 10^{-6} \mathrm{Jm}^{-3} \mathrm{~K}^{-1}, 0.4238 \times 10^{-6}$ $\mathrm{m}^{2} \mathrm{~s}^{-1}, 0.9658 \mathrm{Wm}^{-1} \mathrm{~K}^{-1}, 2.1517 \mathrm{Jm}^{-2} \mathrm{~s}^{-1 / 2} \mathrm{~K}^{-1}$, respectively.

- In homogeneous soil, the lag in maximum or minimum temperature increases linearly, and the logarithm of the temperature amplitude decreases linearly with soil depth.

- By plotting the time lag and wave amplitude against the soil depth, the thermal diffusivity is estimated.

\section{Acknowledgements}

The authors thank the Director and staff members of the India Meteorological Department, Thiruvananthapuram for providing data required for this work and Suresh Kumar S, Department of Higher Secondary Education, Govt. of Kerala for his support in obtaining the topographic map of the site. They are also grateful to the anonymous reviewers for their thorough reviews, helpful comments and suggestions.

\section{References}

Abu-Hamdeh N H and Reeder R C 2000 Soil thermal conductivity: Effects of density, moisture, salt concentration and organic matters; Soil Sci. Soc. Am. J. 64 1285-1290.

Anandakumar K, Venkatesan R and Prabha Thara V 2001 Soil thermal properties at Kalpakkam in coastal south India; Proc. Indian Acad. Sci. (Earth Planet. Sci.) 110(3) 239-245.

Arkhangel'skaya T A 2009 Parameterization and mathematical modeling of the dependence of soil thermal diffusivity on the water content; Eurasian Soil Sci. 42 162-172.

Baier W 1969 Concept of soil moisture availability and their effect on soil moisture estimates from a meteorological budget; Agric. Meteorol. 6(3) 165-178.

Baier W and Robertson G W 1966 A new versatile soil moisture budget; Can. J. Plant. Sci. 46 299-315.

Baver L D, Gardner W H and Gardner N R 1972 Soil Physics; 4th edn (New York: John Wiley and Sons).

Biswas B C 1978 Soil moisture variation under rain fed condition at Pune and Delhi in relation to rainfall; Indian J. Met. Hydrol. Geophys. 29(3) 555-560.

Biswas B C and Dasgupta S K 1979 Estimation of soil moisture at deeper depth from surface layer data; Mausam 30(4) 511-516.

Bocock K L and Adamson J K 1982 Soil temperature in a deciduous woodland in north-west England; Merlewood Research and Development Paper No. 8\%, Grange-over-Sand.

Canuffo D and Bernadi A 1982 An observational study of heat fluxes and their relationships with net radiation; Bound.-Layer Meteorol. 23 359-368.

Chacko P T and Renuka G 2008 Thermal diffusivity of soils in iso-hyperthermic temperature regime by harmonic analysis; Indian J. Radio Space Phys. 37 360-365.
De Vries D A and Afgan N H 1975 Heat and Mass Transfer in the Biosphere (New York: John Wiley and Sons).

Garratt J R 1992 The Atmospheric Boundary Layer (Cambridge: Cambridge University Press).

Guan X D, Huang J P, Guo N, Bi J R and Wang G 2009 Variability of soil moisture and its relationship with surface albedo and soil thermal parameters over the Loess Plateau; Adv. Atmos. Sci. 26(4) 692-700.

Hanks R J and Ashcroft G L 1986 Applied Soil Physics (Berlin: Springer-Verlag).

Hillel D 1982 Introduction to Soil Physics (New York: Academic Press).

Huang J, Zhang W, Zuo J, Bi J, Shi J, Wang X, Chang Z, Huang Z, Yang S, Zhang B, Wang G, Feng G, Yuan J, Zhang L, Zuo H, Wang S, Fu C and Cho J 2008 An overview of the Semi-Arid Climate and Environment Research Observatory over the Loess Plateau; Adv. Atmos. Sci. 25(6) 906-921.

Kaushik S B, Sharma G S and Mokhashi B G 1965 Preliminary studies on subsoil temperatures at Jodhpur; Def. Sci. J. 15 30-35.

Lamba B S and Sunita Bhandari 1998 Some aspects of thermal diffusivity for various soil layers in different harmonics; Mausam 49(2) 255-258.

Liu H Z, Wang B M and Fu C B 2008 Relationships between surface albedo, soil thermal parameters and soil moisture in the semi-arid area of Tongyu, northeastern China; Adv. Atmos. Sci. 25(5) 757-764.

Menon P A and Rajan C K 1989 Climate of Kerala (Cochin: Classic Publications).

Nwadibia N O, Ugwa E I and Aduloju K A 2010 Theoretical analysis of the influence of the thermal diffusivity of clay soil on the thermal energy distribution in clay soil of Abakaliki, Nigeria; Res. J. Appl. Sci. Eng. Technol. 2(3) $216-221$.

Oke T R 1978 Boundary Layer Climates (New York: John Wiley and Sons).

Padmanabhamurty B, Amaralingeswara Rao $\mathrm{K}$ and Mukherjee R 1998 A preliminary analysis of soil temperature at five different sites under land surface processes experiment in the Sabarmati river basin; Indian J. Radio Space Phys. 27(5) 199-206.

Peled E, Dutra E, Viterbo P and Angert A 2010 Technical note: Comparing and ranking soil drought indices performance over Europe, through remote-sensing of vegetation; Hydrol. Earth Syst. Sci. 14 271-277.

Peters-Lidard C D, Blackburn E, Liang X and Wood E F 1998 The effect of soil thermal conductivity parameterization on surface energy fluxes and temperatures; J. Atmos. Sci. 55 1209-1224.

Prasada Rao G S L H V 2003 Agricultural Meteorology (Thrissur: Kerala Agricultural University Press).

Ramdas L A and Mallik A K 1942 Studies on soil; Proc. Indian Acad. Sci. 16 16-22.

Rezapour N, Fattahi M and Bidokhti A A 2010 Possible soil thermal response to seismic activities in Alborz region (Iran); Nat. Hazards Earth Syst. Sci. 10 459-464.

Sellers D W 1972 Physical Climatology (Chicago: University of Chicago Press).

Sen Lu, Ren Tusheng, Gong Yuanshi and Horton Robert 2007 An improved model for predicting soil thermal conductivity from water content at room temperature; Soil Sci. Soc. Am. J. 71(1) 8-14.

Sivadas T K 2007 Sensors and measurement systems for environmental, marine, fisheries and agricultural applications (Cochin: Central Institute of Fisheries Technology).

Tamai K 2010 Effects of environmental factors and soil properties on tropographic variations of soil respiration; Biogeosci. 7 1133-1142. 
Tessy Chacko P and Renuka G 2002 Temperature mapping, thermal diffusivity and subsoil heat flux at Kariavattom of Kerala; Proc. Indian Acad. Sci. (Earth Planet. Sci.) 111(1) 79-85.

Tyson E Ochsner, Horton Robert and Ren Tusheng 2001 A new perspective on soil thermal properties; Soil Sci. Soc. Am. J. 65(5) 1641-1647.

Van Wijk W R 1965 Soil microclimate, its creation, observation and modification; Met. Monogr. 6(28) 59-73.

Verhoef A, Van den Hurk B J J M, Jacobs A F G and Heusinkveld B G 1996 Thermal soil properties for vineyard ( EFEDA-I ) and savanna (HAPEX-Sahel); Agric. For. Meteorol. 78 1-18.

Wang K C, Wang P C, Liu J M, Sparrow M, Haginoya S and Zhou X J 2005 Variation of surface albedo and soil thermal parameters with soil moisture content at a semidesert site on the western Tibetan Plateu; Bound.-Layer Meteorol. 116 117-129.

Wetzel P J and Woodward R H 1987 Soil moisture estimation using GOES-VISS infrared data: A case study with a simple statistical method; J. Clim. Appl. Meteorol. 26 $107-117$.

MS received 9 October 2013; revised 17 July 2014; accepted 23 July 2014 